\title{
Effect of norfloxacin and moxifloxacin on melanin synthesis and antioxidant enzymes activity in normal human melanocytes
}

\author{
Artur Beberok • Dorota Wrześniok • \\ Michał Otręba • Maciej Miliński · Jakub Rok • \\ Ewa Buszman
}

Received: 4 September 2014 / Accepted: 27 November 2014/Published online: 30 November 2014

(C) The Author(s) 2014. This article is published with open access at Springerlink.com

\begin{abstract}
Fluoroquinolone antibiotics provide broadspectrum coverage for a number of infectious diseases, including respiratory as well as urinary tract infections. One of the important adverse effects of these drugs is phototoxicity which introduces a serious limitation to their use. To gain insight the molecular mechanisms underlying the fluoroquinolones-induced phototoxic side effects, the impact of two fluoroquinolone derivatives with different phototoxic potential, norfloxacin and moxifloxacin, on melanogenesis and antioxidant enzymes activity in normal human melanocytes HEMa-LP was determined. Both drugs induced concentration-dependent loss in melanocytes viability. The value of $\mathrm{EC}_{50}$ for these drugs was found to be $0.5 \mathrm{mM}$. Norfloxacin and moxifloxacin suppressed melanin biosynthesis; antibiotics were shown to inhibit cellular tyrosinase activity and to reduce melanin content in melanocytes. When comparing the both analyzed fluoroquinolones, it was observed that norfloxacin possesses greater inhibitory effect on tyrosinase activity in melanocytes than moxifloxacin. The extent of oxidative stress in cells was assessed by measuring the activity of antioxidant enzymes: SOD, CAT, and GPx. It was observed that norfloxacin caused higher depletion of antioxidant status in melanocytes when compared with moxifloxacin. The obtained results give a new insight into the mechanisms of fluoroquinolones toxicity directed to pigmented tissues. Moreover, the presented differences in modulation of biochemical processes in melanocytes may be
\end{abstract}

A. Beberok $(\bowtie) \cdot$ D. Wrześniok · M. Otręba · M. Miliński ·

J. Rok · E. Buszman

Department of Pharmaceutical Chemistry, Faculty of Pharmacy,

Medical University of Silesia, Jagiellońska 4, 41-200 Sosnowiec,

Poland

e-mail: abeberok@sum.edu.pl an explanation for various phototoxic activities of the analyzed fluoroquinolone derivatives in vivo.

Keywords Norfloxacin - Moxifloxacin - Melanin · Tyrosinase activity $\cdot$ Oxidative stress

\section{Introduction}

Fluoroquinolones constitute a relatively new class of antibiotics since they were introduced to therapy in 1980 . These antibiotics display a broad spectrum of antibacterial activity including strong effects on Gram-negative aerobic and anaerobic organisms as well as on Gram-positive and atypical pathogens [1, 2]. The mechanism of action of fluoroquinolones involves inhibition of deoxyribonucleic acid (DNA) gyrase (topoisomerase II) and topoisomerase IV, enzymes involved in bacterial DNA replication, transcription, repair, and recombination [3, 4]. Norfloxacin, with potent activity against urinary pathogens, is used for the treatment of common as well as complicated urinary tract infections, whereas moxifloxacin is approved and considered as an alternative to $\beta$-lactams and macrolides for the treatment of acute bacterial sinusitis and lower respiratory tract infections [2, 5]. Despite their excellent antibacterial properties, fluoroquinolones cause phototoxic reactions as one of the main side effects, what introduces a serious limitation to their use. Literature data report many examples of fluoroquinolones-mediated skin phototoxicity. These reactions include skin lesions with different degree of severity, from cutaneous reactions (erythema, rashes, toxic dermatitis, Steven-Johnson syndrome, or toxic epidermal necrolysis) to skin cancer (carcinoma and melanoma) [6-11]. The photoreactivity of fluoroquionolones is markedly modulated by the nature and position of the 
substituents attached to the quinolone's structure. These antibiotics undergo a variety of photochemical processes such as dehalogenation, oxidation of an amino substituent at C-7, decarboxylation, and the formation of reactive oxygen species (ROS), such as hydroxyl radical, superoxide anion, hydrogen peroxide (Type I), and singlet oxygen (Type II). These processes are able to modify cell components, including lipids, proteins, and nucleic acids [3, 8]. Halogenation (chlorine, fluorine) of position 8 together with fluorination of position 6 (the so-called double-halogenated quinolones) has demonstrated significant phototoxic potential [2, 8]. Therefore, lomefloxacin and sparfloxacin have been reported to have relatively high phototoxic potential as compared with other fluoroquinolones, e.g., ciprofloxacin or norfloxacin which are capable to induce severe phototoxic reactions when the patient is exposed to high drug dosages and high levels of UV radiation. [3, 8, 12]. Moxifloxacin is a new fluoroquinolone antibiotic with a methoxyl group at position 8 of the quinolone system what confers photostability and reduced phototoxicity on the molecule $[3,6,8]$.

Melanocytes form a heterogeneous group of cells in human body. Although all of them have ability to produce melanin, their functions in all target places are much wider than only the melanin synthesis. They protect epidermal cells from damage by limiting the penetration of UV rays through the epidermal layers and scavenging reactive oxygen species generated in response to UV exposure. Moreover, melanocytes are also phagocytic cells involved in the inflammatory response [13-15]. In the human body, melanocytes are present not only in the epidermis, hair, and iris where they give a color to these structures but also in the inner ear, central nervous system, and heart $[13,15]$.

Epidermal melanin can be divided into two classes: eumelanin with its known photoprotective properties and pheomelanin which is presumed to be phototoxic $[14,16]$. Moreover, melanin has an affinity for drugs and other chemical substances. Because of these properties, melanin efficiently filters toxic substances and protects tissues from oxidative and chemical stress. However, with chronic exposure to toxic substances, the properties of melanin change so that under severe oxidative stress and binding of excessive amount of toxins, melanin itself may induce damage to cells [17]. In addition, drug bound to melanin forms a depot that releases the drug over a long period and increases the level of noxious substances stored in melanin, what may cause degeneration in melanin-containing cells (especially in the skin or eye) and surrounding tissues [18].

Previously, we have documented that ciprofloxacin [19] and lomefloxacin [20] modulate biochemical processes in normal human melanocytes, suggesting a mechanism for the drug-induced toxicity on pigmented tissues. Whether the same mechanism can be attributed to other fluoroquinolone derivatives, i.e., norfloxacin and moxifloxacin, with different toxic potential, remains to be determined.

The aim of the present work was to examine the effect of norfloxacin and moxifloxacin on melanogenesis and antioxidant defense system in cultured normal human melanocytes HEMa-LP.

\section{Materials and methods}

\section{Materials}

Norfloxacin, phosphated-buffered saline (PBS), 3,4-dihydroxy-L-phenylalanine (L-DOPA) and amphotericin B were purchased from Sigma-Aldrich Inc.(USA). Moxifloxacin hydrochloride (Avelox ${ }^{\mathrm{TM}}$ solution for i.v. use containing $400 \mathrm{mg}$ of moxifloxacin in $0.8 \%$ saline) was obtained from Bayer Healthcare Pharmaceuticals Inc. (Germany). Neomycin sulfate was obtained from Amara (Poland). Penicillin was acquired from Polfa Tarchomin (Poland). Growth medium M-254 and human melanocyte growth supplement-2 (HMGS-2) were obtained from Cascade Biologics (UK). Trypsin/EDTA was obtained from Cytogen (Poland). Cell Proliferation Reagent WST-1 was purchased from Roche GmbH (Germany). The remaining chemicals were produced by POCH S.A. (Poland).

\section{Cell culture}

The normal human epidermal melanocytes HEMa-LP (Cascade Biologics, UK) were grown according to the manufacturer's instruction. The cells were cultured in M-254 basal medium supplemented with HMGS-2, penicillin $(100 \mathrm{U} / \mathrm{ml})$, neomycin $(10 \mu \mathrm{g} / \mathrm{ml}$, ) and amphotericin B $(0.25 \mu \mathrm{g} / \mathrm{ml})$ at $37{ }^{\circ} \mathrm{C}$ in $5 \% \mathrm{CO}_{2}$. All experiments were performed using cells in the passages 6-9.

\section{Cell viability assay}

The viability of melanocytes was evaluated by the WST-1 (4-[3-(4-iodophenyl)-2-(4-nitrophenyl)-2H-5-tetrazolio]1,3-benzene disulphonate) colorimetric assay according to the method described earlier $[19,21]$.

Measurement of melanin content

The melanocytes were seeded in T-25 flasks at a density of $1 \times 10^{5}$ cells per flask. Norfloxacin or moxifloxacin treatment in a concentration range from 0.005 to $0.5 \mathrm{mM}$ began $48 \mathrm{~h}$ after seeding. After $24 \mathrm{~h}$ of incubation, the cells were washed three times with PBS and detached with trypsin-EDTA. Cell pellets were placed into Eppendorf tubes, dissolved in $100 \mu \mathrm{l}$ of $1 \mathrm{M} \mathrm{NaOH}$ at $80{ }^{\circ} \mathrm{C}$ for $1 \mathrm{~h}$, 
and then centrifuged for $20 \mathrm{~min}$ at $16,000 \times \mathrm{g}$. The supernatants were placed into a 96-well microplate, and absorbance was measured at $405 \mathrm{~nm}$-a wavelength at which melanin absorbs light [22]. A standard synthetic melanin curve $(0-400 \mu \mathrm{g} / \mathrm{ml})$ was performed in triplicate for each experiment. Melanin content in norfloxacin and moxifloxacin-treated cells was expressed as the percentage of the controls (untreated melanocytes).

Tyrosinase activity assay

Tyrosinase activity in HEMa-LP cells was determined by measuring the rate of oxidation of L-DOPA to DOPAchrome, according to the method described by Kim et al. [23] and Busca et al. [24], with a slight modification. The cells were cultured at a density of $1 \times 10^{5}$ cells in T-25 flasks for $48 \mathrm{~h}$. After 24-h incubation with norfloxacin or moxifloxacin (concentration range from 0.005 to $0.5 \mathrm{mM}$ ), cells were washed three times with PBS, lysed, and clarified by centrifugation at $10,000 \times g$ for $5 \mathrm{~min}$. A tyrosinase substrate L-DOPA ( $2 \mathrm{mg} /$ $\mathrm{ml}$ ) was prepared in the same lysis phosphate buffer. $100 \mu \mathrm{l}$ of each lysate were put in a 96-well plate, and the enzymatic assay was initiated by the addition of $40 \mu \mathrm{l}$ of L-DOPA solution at $37^{\circ} \mathrm{C}$. Absorbance was measured every $10 \mathrm{~min}$ for at least $1.5 \mathrm{~h}$ at $475 \mathrm{~nm}$ using a microplate reader. Tyrosinase activity was expressed as the percentage of the controls.

A cell-free assay system was used to test for direct effects on tyrosinase activity. $130 \mu \mathrm{l}$ of phosphate buffer containing norfloxacin or moxifloxacin in a concentration range from 0.005 to $1.0 \mathrm{mmol} / \mathrm{l}$ were mixed with $20 \mu \mathrm{l}$ of mushroom tyrosinase (1,000 units), and $100 \mu \mathrm{l}$ of L-DOPA solution $(2 \mathrm{mg} / \mathrm{ml})$ was added to each well. The assay mixtures were incubated at $37{ }^{\circ} \mathrm{C}$ for $20 \mathrm{~min}$, and absorbance of DOPAchrome was measured at $475 \mathrm{~nm}$ in a microplate reader. The mushroom tyrosinase activities were calculated in the relation to the controls (samples without drug). The value $\mathrm{IC}_{50}$ (the concentration of a drug that inhibits a standard response by $50 \%$ ) was calculated on the basis of a dose-dependent inhibition curve, as described by Chung et al. [25].

Superoxide dismutase assay

Superoxide dismutase (SOD) activity was measured using an assay kit (Cayman, MI, USA) according to the manufacturer's instruction. One unit of SOD was defined as the amount of enzyme needed to produce $50 \%$ dismutation of superoxide radical. SOD activity was expressed in U/mg protein.

Catalase assay

Catalase (CAT) activity was measured using an assay kit (Cayman, MI, USA) according to the manufacturer's instruction. One unit of CAT was defined as the amount of enzyme that causes the formation of $1.0 \mathrm{nmol}$ of formaldehyde per minute at $25{ }^{\circ} \mathrm{C}$. CAT activity was expressed in $\mathrm{nmol} / \mathrm{min} / \mathrm{mg}$ protein.

\section{Glutathione peroxidase assay}

Glutathione peroxidase (GPx) activity was measured using an assay kit (Cayman, MI, USA) according to the manufacturer's instruction. One unit of GPx was defined as the amount of enzyme that catalyzes the oxidation of $1 \mathrm{nmol}$ of NADPH per minute at $25{ }^{\circ} \mathrm{C}$. GPx activity was expressed in $\mathrm{nmol} / \mathrm{min} / \mathrm{mg}$ protein.

Statistical analysis

In all experiments, mean values of at least three separate experiments $(n=3)$ performed in triplicate \pm standard error of the mean (S.E.M.) were calculated. The results were analyzed statistically using GraphPad Prism 6.01 Software. A value of $p<0.05\left(^{*}\right)$ or $p<0.01 \quad(* *)$, obtained with a Student's $t$ test by comparing the data with those for control (cells without drugs), was considered statistically significant.

\section{Results}

The effect of norfloxacin and moxifloxacin on cell viability

Melanocytes were treated with norfloxacin or moxifloxacin in a range of concentrations from 0.001 to $1.0 \mathrm{mM}$ for $24 \mathrm{~h}$. The cell viability was determined by the WST-1 test assay. As shown in Fig. 1, norfloxacin induced an evident concentration-dependent loss in cell viability. Cells treated with $0.001,0.01,0.1,0.25,0.5,0.75$, and 1.0 of norfloxacin lost $9.8,20.2,25.7,38.3,51.2,74.1$, and $81.5 \%$ in viability, respectively. In contrast to norfloxacin, moxifloxacin in concentrations from $0.001 \mathrm{mM}$ to $0.1 \mathrm{mM}$ did not influence the cell viability. After incubation of cells with $0.25,0.5,0.75$, and 1.0 of moxifloxacin, the loss in cell viability was $29.7,50.2,89.1$, and $89.9 \%$, respectively. For the both analyzed drugs, the value of $\mathrm{EC}_{50}$ (i.e., the amount of a drug that produces loss in cell viability by $50 \%$ ) was $0.5 \mathrm{mM}$.

The effect of norfloxacin and moxifloxacin on melanization process

The effectiveness of melanization process was estimated by measuring the melanin content and cellular tyrosinase activity in melanocytes treated with norfloxacin or 


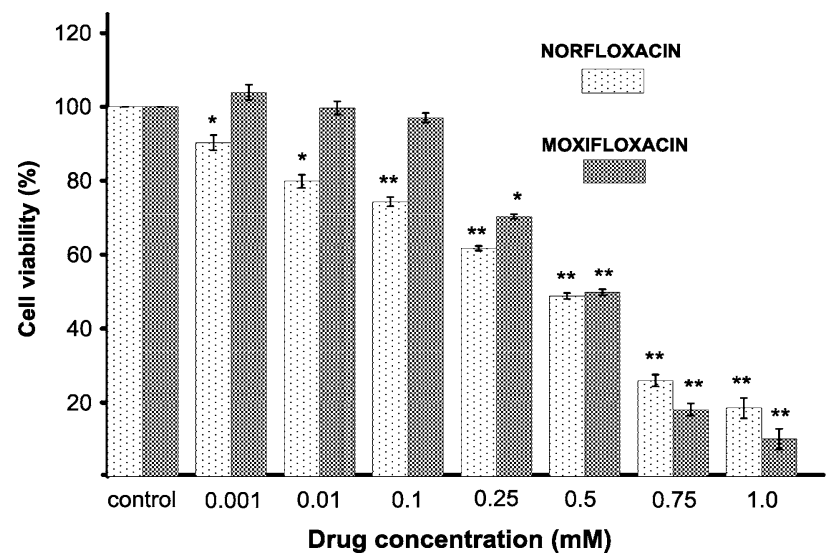

Fig. 1 The effect of norfloxacin and moxifloxacin on viability of melanocytes. Cells were treated with various drugs concentrations $(0.001-1.0 \mathrm{mM})$ and examined by the WST-1 assay. Data are expressed as $\%$ of the controls. Mean values \pm S.E.M. from three independent experiments $(n=3)$ performed in triplicate are presented. $* p<0.05$ versus the control samples; $* * p<0.005$ versus the control samples

moxifloxacin in concentrations from $0.005 \mathrm{mM}$ to $0.5 \mathrm{mM}$, for $24 \mathrm{~h}$. After determining a calibration curve, the melanin content per cell was estimated as $37.3 \pm 0.6$ to $28.3 \pm 0.9 \mathrm{pg} /$ cell and $36.2 \pm 0.5$ to $28.1 \pm 3.04 \mathrm{pg} / \mathrm{cell}$ for melanocytes treated with norfloxacin and moxifloxacin, respectively, while the value determined for the control (cell without drug) was $36.6 \pm 3.4 \mathrm{pg} / \mathrm{cell}$. The obtained results, recalculated for culture $\left(1 \times 10^{5}\right.$ cells $)$, were finally expressed as a percentage of the controls (Fig. 2a). Both analyzed drugs in concentration of $0.005,0.025$, and 0.05 had no statistically significant effect on melanin content in melanocytes. In cells treated with norfloxacin or moxifloxacin at concentrations of $0.25 \mathrm{mM}$ and $0.5 \mathrm{mM}$ for $24 \mathrm{~h}$, melanin production decreased by about $12 \%$ and $19 \%$ or $10 \%$ and $22 \%$, respectively.

Tyrosinase activity in HEMa-LP cells treated with moxifloxacin decreased in a manner correlating well with the inhibitory effect on melanin production (Fig. 2b). After 24-h incubation tyrosinase activity was suppressed to $82 \%$ at $0.25 \mathrm{mM}$ and to $70 \%$ at $0.5 \mathrm{mM}$ when compared with the control. The use of moxifloxacin in lower concentrations $(0.005,0.025$ and 0.05$)$ had no statistically significant effect on the enzyme activity. In contrast to moxifloxacin, norfloxacin significantly decreased tyrosinase activity by $10,25,38$, and $45 \%$ at concentrations of $0.025,0.05,0.25$, and 0.5 , respectively. Only the lowest drug concentration $(0.005 \mathrm{mM})$ had no effect on the enzyme activity.

The analyzed drugs significantly decreased mushroom tyrosinase activity (Table 1) in a concentration-dependent manner. The concentration of norfloxacin and moxifloxacin required for $50 \%$ inhibition of mushroom tyrosinase activity $\left(\mathrm{IC}_{50}\right)$ was $0.7 \mathrm{mM}$ and $1.2 \mathrm{mM}$, respectively, what supports the cellular results indicating higher
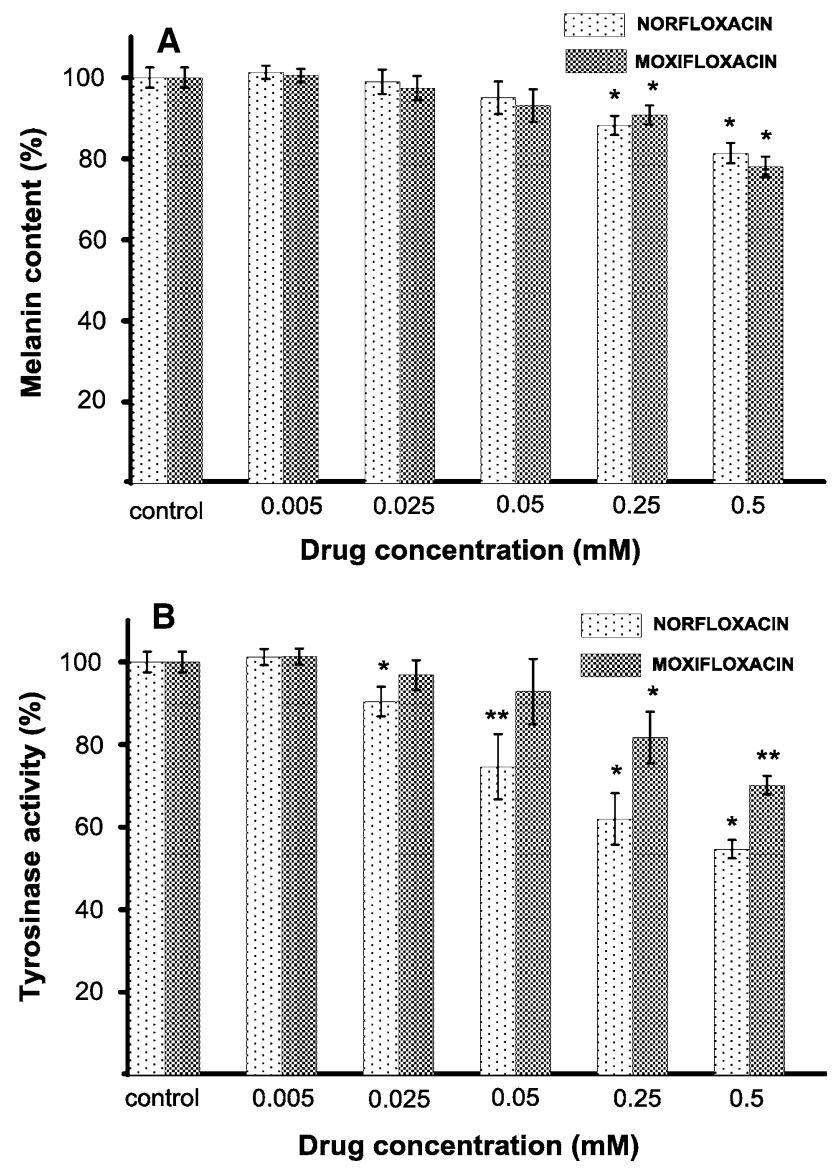

Fig. 2 The effect of norfloxacin and moxifloxacin on melanin content (a) and tyrosinase activity (b) in melanocytes. Cells were cultured with norfloxacin or moxifloxacin in concentrations from 0.005 to $0.5 \mathrm{mM}$ for $24 \mathrm{~h}$. The melanin content and cellular tyrosinase activity were measured as described in "Materials and methods" section. Results are expressed as percentages of the controls. Data are mean \pm S.E.M. of at least three independent experiments $(n=3)$ performed in triplicate. $* p<0.05$ versus the control samples; $* * p<0.005$ versus the control samples

inhibitory effect of norfloxacin than moxifloxacin on this enzyme activity.

The effect of norfloxacin and moxifloxacin on antioxidant enzymes activity

To explain the effect of the tested antibiotics on reactive oxygen species metabolism, the activities of the antioxidative enzymes were characterized. Human melanocytes HEMa-LP were exposed to norfloxacin or moxifloxacin in concentrations of $0.05 \mathrm{mM}$ and $0.5 \mathrm{mM}\left(\mathrm{EC}_{50}\right)$ for $24 \mathrm{~h}$. The first enzyme measured was SOD, i.e., the enzyme which catalyzes the formation of hydrogen peroxide from superoxide anion. Both analyzed drugs enhanced the SOD activity in a concentration-dependent manner (Fig. 3a). The treatment of cells with $0.05 \mathrm{mM}$ and $0.5 \mathrm{mM}$ of norfloxacin or moxifloxacin increased the SOD activity by 15 
Table 1 The inhibitory effect of norfloxacin and moxifloxacin on mushroom tyrosinase activity

\begin{tabular}{lll}
\hline Analyzed drug & $\begin{array}{l}\text { Inhibition } \pm \\
\text { S.E.M }\end{array}$ & $\mathrm{IC}_{50}^{\mathrm{b}}(\mathrm{mM})$ \\
\hline Norfloxacin $0.005 \mathrm{mM}$ & $77.3 \pm 3.4$ & 0.70 \\
Norfloxacin $0.05 \mathrm{mM}$ & $67.7 \pm 2.1$ & \\
Norfloxacin $0.5 \mathrm{mM}$ & $53.4 \pm 2.3$ & \\
Norfloxacin $1.0 \mathrm{mM}$ & $44.7 \pm 3.6$ & \multirow{2}{*}{1.20} \\
Moxifloxacin $0.005 \mathrm{mM}$ & $76.6 \pm 1.3$ & \\
Moxifloxacin $0.05 \mathrm{mM}$ & $70.9 \pm 1.7$ & \\
Moxifloxacin $0.5 \mathrm{mM}$ & $61.8 \pm 3.1$ & \\
Moxifloxacin $1.0 \mathrm{mM}$ & $56.1 \pm 2.5$ & \\
\hline
\end{tabular}

$\overline{\text { a Samples-contained phosphate buffer with different norfloxacin or }}$ moxifloxacin concentrations, mushroom tyrosinase (1,000 units), and L-DOPA solution $(2 \mathrm{mg} / \mathrm{ml})$. Tyrosinase activity was measured as described in "Materials and methods" section

b $50 \%$ inhibitory concentration

and $32 \%$, or by 54 and $81 \%$, respectively, as compared with the controls. CAT and GPx work together to catalyze the breakdown of hydrogen peroxide, produced by SOD, to water. The intracellular CAT activity was significantly increased by 54 or $86 \%$ for cells treated with norfloxacin or moxifloxacin at $0.05 \mathrm{mM}$ concentration. Norfloxacin in concentration of $0.5 \mathrm{mM}\left(\mathrm{EC}_{50}\right)$ increased the CAT activity only by $9 \%$, whereas moxifloxacin increased the enzyme activity by $35 \%$ (Fig. 3b). The activity of GPx increased by 20 or $40 \%$ for norfloxacin or moxifloxacin in concentration of $0.05 \mathrm{mM}$ and decreased by 13 or $12 \%$ for cells treated with $0.5 \mathrm{mM}\left(\mathrm{EC}_{50}\right)$, respectively, in comparison to control cells (Fig. 3c).

\section{Discussion}

The fluoroquinolone antibiotics are used in the treatment of a wide range of bacterial infections, but are recognized as a group to be associated with drug-induced phototoxicity, especially directed to skin tissues $[2,3,8,10]$. Among clinically developed fluoroquinolones phototoxicity ranks as follows: sparfloxacin $\geq$ lomefloxacin (both carrying a halogen in position 8) $>$ ciprofloxacin $\geq$ norfloxacin $>$ ofloxacin $\gg$ moxifloxacin $[1,2]$. Although the phototoxicity of fluoroquinolones is well documented, the molecular mechanisms have not yet been precisely determined.

Many investigators have demonstrated the affinity of natural and synthetic melanins for various drugs by in vitro studies [18, 26, 27]. By inhibiting or significantly restricting drug access to cell receptors, melanins protect organism against undesirable drugs' side effects. However, long-term
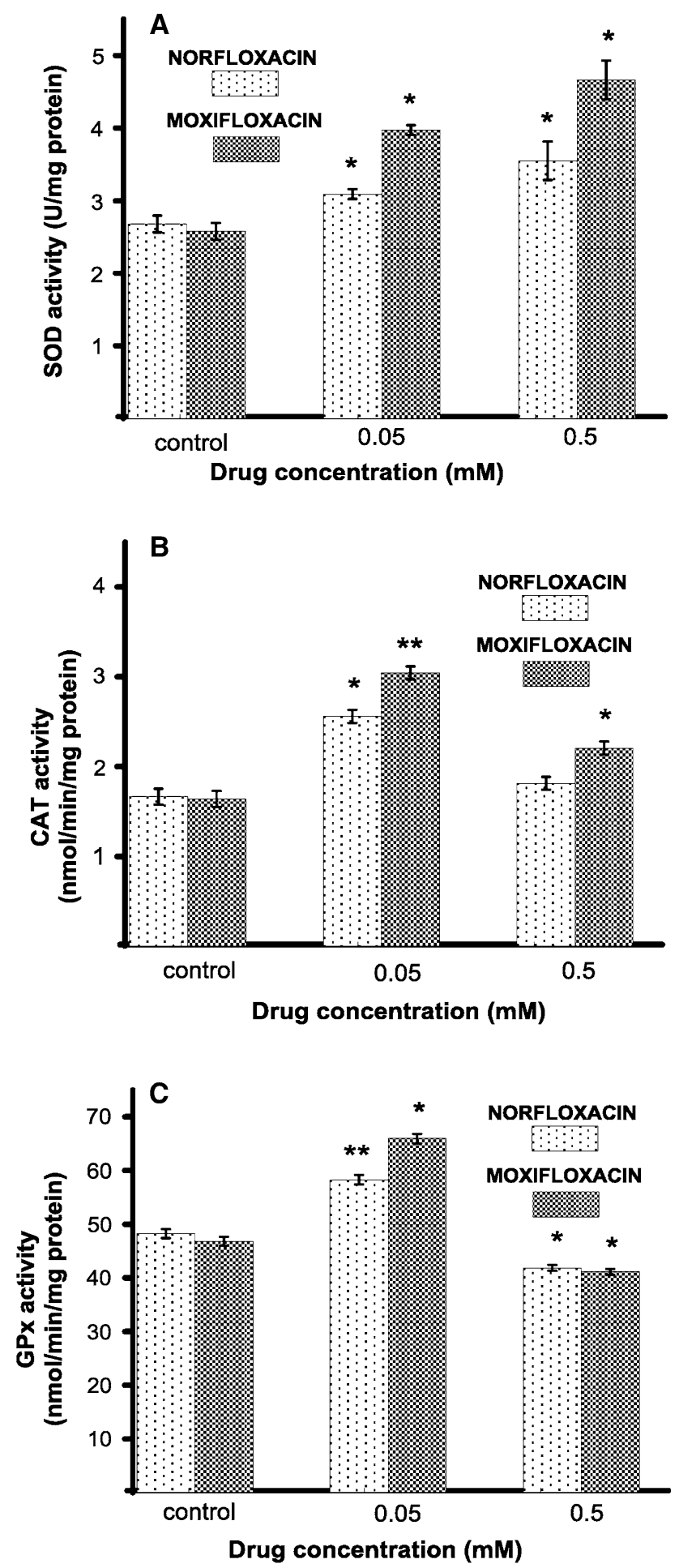

Fig. 3 The superoxide dismutase (SOD) (a), catalase (CAT) (b), and glutathione peroxidase (GPx) (c) activity in HEMa-LP cells after 24-h incubation with 0.05 or $0.5 \mathrm{mM}$ of norfloxacin and moxifloxacin. Data are mean \pm S.E.M. of at least three independent experiments $(n=3)$ performed in triplicate. $* p<0.05$ versus the control samples; $* * p<0.005$ versus the control samples 
exposure and slow release of drugs or their metabolites from bonds may increase the level of noxious substances stored on melanin, which may cause degeneration in the melanin-containing cells (e.g., in the skin and eye) and surrounding tissues $[17,18]$.

Previously, we have demonstrated that norfloxacin and moxifloxacin interact specifically with melanin, what may be a reason for these drugs accumulation in melanin-rich tissues $[28,29]$. When comparing the binding parameters obtained for moxifloxacin [28] with those of norfloxacin, sparfloxacin [28], and lomefloxacin [20], it can be observed that the total number of binding sites in the melanin biopolymer for moxifloxacin was significantly lower than that for the other analyzed fluoroquinolones. Simultaneously, the moxifloxacin-melanin complexes were characterized by lower values of stability constants. The different affinity and capacity for binding of the studied fluoroquinolone derivatives to melanin may explain various toxic activities of these drugs on pigmented tissues in vivo.

Melanin is a biopolymer synthesized by melanocytes in discrete organelles - melanosomes [15, 30]. Therefore, in this study, we have used the culture of normal human epidermal melanocytes as an in vitro experimental model system. The study was conducted to elucidate the possible involvement of melanin and melanocytes in the mechanisms of fluoroquinolones-induced toxic effects. The melanin content and tyrosinase activity were chosen as the biomarkers for modulatory effect of norfloxacin and moxifloxacin on melanogenesis, whereas the SOD, CAT, and GPx activities as the markers for oxidative stress in normal human melanocytes HEMa-LP.

It was observed that moxifloxacin in concentrations from 0.001 to $0.1 \mathrm{mM}$ did not have any significant effect on melanocytes viability. Higher drug concentrations (from 0.25 to $1.0 \mathrm{mM}$ ) resulted in the loss of cell viability in a concentration-dependent manner (Fig. 1). The use of norfloxacin caused higher reduction in cell viability when this drug was applied in lower concentrations. The value of $\mathrm{EC}_{50}$ for both analyzed drugs was determined to be $0.5 \mathrm{mM}$. For the same cell line, the value of $\mathrm{EC}_{50}$ established for other fluoroquinolones, ciprofloxacin and lomefloxacin, was $0.5 \mathrm{mM}$ [19] and $0.75 \mathrm{mM}$ [20], respectively, what indicates that norfloxacin and moxifloxacin are similarly cytotoxic.

Melanin is synthesized in the presence of tyrosinase, a copper-containing metalloglycoprotein which is attributed to possess multiple catalytic activities utilizing L-tyrosine, dihydroxyphenylalanine (L-DOPA), and 5,6-dihydroxyindole as substrates [31]. The rate limiting step in melanin synthesis is the hydroxylation reaction involving the conversion of the amino acid L-tyrosine to dihydroxyphenylalanine under the control of tyrosinase. DOPA is subsequently converted to a stable intermediate DOPAchrome, which undergoes a spontaneous decarboxylation to 5,6-dihydroxyindole (DHI) or an enzymatic tautomerization (by tyrosinase-related protein TRP2) to 5,6-dihydroxyindole-2carboxylic acid (DHICA). Both of these products are then oxidized to quinones, which are polymerized to eumelanin. In the presence of sulphydryl compounds (cysteine or glutathione), the synthetic pathway is shifted toward the formation of pheomelanins. [15, 30-32].

Since tyrosinase is a major regulator of melanin synthesis, we have examined a direct effect of norfloxacin and moxifloxacin on the activity of this enzyme. Norfloxacin in concentrations of $0.025,0.05,0.25$, and 0.5 suppressed the tyrosinase activity in melanocytes to $90,75,62$, and $55 \%$, respectively (Fig. 2b). The inhibitory effect of moxifloxacin on cellular tyrosinase activity was observed only at higher drug concentrations (from 0.25 and $0.5 \mathrm{mM}$ ). Thus, norfloxacin demonstrates greater inhibitory effect on tyrosinase activity in melanocytes than moxifloxacin. We repeated the experiment with commonly used mushroom tyrosinase and obtained similar results (Table 1). Our findings indicate that an inhibitory effect of the studied antibiotics on melanogenesis is probably due to their direct inhibition of tyrosinase activity. The results of our prior studies $[19,20]$ and those obtained in this study reveal that moxifloxacin demonstrates the lowest inhibitory effect on cellular tyrosinase activity in comparison to norfloxacin, ciprofloxacin, or lomefloxacin.

The analysis of melanin formation in cells cultured in the presence or absence of a drug showed that norfloxacin and moxifloxacin in concentrations of $0.25 \mathrm{mM}$ or $0.5 \mathrm{mM}$ suppressed the melanin content to 88 and $81 \%$, or to 90 or $78 \%$, respectively (Fig. 2a). In comparison to ciprofloxacin [19] and lomefloxacin [20], the drugs analyzed in this study caused lower reduction in melanin content.

It has been suggested that free radicals generated after fluoroquinolones treatment play an important role in these antibiotics' toxicity [3, 8, 33]. Several antioxidant enzymes, including superoxide dismutase (SOD), catalase (CAT), and glutathione peroxidase (GPx), are effective in removing destructive ROS. Insufficient activity of intracellular antioxidant enzymes can cause damage to cell structures. When unbalanced, it may lead to oxidation of polyunsaturated fatty acids in lipids, amino acids in proteins, and damage to DNA [34, 35].

Melanin is known to be a scavenger of free radicals and it has been suggested that it possesses the superoxide dismutase activity [36]. Moreover, this biopolymer acts as a biochemical dustbin, mopping up potentially toxic agents [18]. Such properties may be important for protecting the pigment cells as well as surrounding tissues from the natural toxins, xenobiotics, oxygen and free radicals, including ROS [14].

In the present study, it has been observed for the first time that norfloxacin and moxifloxacin cause significant 
changes in the activities of the antioxidant enzymes: SOD, CAT, and GPx in melanocytes. SOD protects cells by dismutating superoxide anion into the proradical hydrogen peroxide, which in turn is inactivated to oxygen and water by catalase or other $\mathrm{H}_{2} \mathrm{O}_{2}$-removing enzymes such as glutathione peroxidase [34]. In melanocytes, catalase is the main enzyme responsible for degrading hydrogen peroxide [37]. If $\mathrm{H}_{2} \mathrm{O}_{2}$ is not effectively cleared, level of reactive hydroxyl radicals may increase due to iron-catalyzed Fenton-type reactions [34]. Here presented a concentrationdependent increase in SOD activity after exposure of melanocytes to norfloxacin and moxifloxacin (Fig. 3a) might be the main reason for overproduction of the superoxide anion and subsequent formation of $\mathrm{H}_{2} \mathrm{O}_{2}$, what leads to the increase in CAT activity. Hsiao et al. [38] have shown that an other fluoroquinolone derivative, namely trovafloxacin, causes mitochondrial peroxynitrite stress in a mouse model leading to the disruption of mitochondrial enzymes and gene regulation. The observed in the present study lower increase of SOD activity in melanocytes after cells exposure to norfloxacin than to moxifloxacin may be caused by this drug higher ability to form reactive nitrogen species (RNS), such as peroxynitrite which may be generated in the presence of high level of superoxide anion leading to SOD inactivation [39]. Moreover, Martinez et al. [33] have proved the ability of norfloxacin to generate high amounts of superoxide anion. Treatment of cells with norfloxacin and moxifloxacin in concentration of $0.05 \mathrm{mM}$ caused higher increase in CAT activity than in concentration of $0.5 \mathrm{mM}$ (Fig. 3b). When comparing the both analyzed drugs, it can be observed that the increase of CAT activity in melanocytes exposed to norfloxacin is significantly lower than in cells exposed to moxifloxacin. Qin and Liu [40] have demonstrated that fluoroquinolones could bind into CAT central cavity what may cause the conformational changes of this enzyme as well as lead to inhibition of its molecular activity. It could be then suggested, that norfloxacin possesses higher ability for binding to CAT central cavity than moxifloxacin and therefore, in its presence higher reduction of this enzyme activity may be observed. This phenomenon indicates for higher depletion of antioxidant status in melanocytes over norfloxacin treatment as compared with moxifloxacin. In addition, the tested antibiotics in concentration of $0.5 \mathrm{mM}$ decreased GPx activity (Fig. 3c). Thus, it may be assumed that alterations in SOD, CAT, and GPx activity play a critical role in these drugs toxicity as a result of redundant superoxide anion and $\mathrm{H}_{2} \mathrm{O}_{2}$ level that cannot be eliminated.

One has to take into consideration that norfloxacin and moxifloxacin concentrations found to have an inhibitory effect on melanogenesis and antioxidant defense system in normal human melanocytes are about 16-, 160-fold higher [41], and 8-, 80-fold higher [42] for norfloxacin and moxifloxacin, respectively, than the concentrations normally observed in vivo. However, we have previously demonstrated that norfloxacin [28] and moxifloxacin [29] form complexes with melanin, what may lead to the accumulation of these drugs in melanin reach tissues. Such accumulation increases the drugs concentrations and may induce some toxic effects on melanin-containing cells and surrounding tissues. Thus, it is possible that norfloxacin and moxifloxacin concentrations in melanocytes may be significantly higher than that in serum and therefore the reduction of melanin content, the inhibition of tyrosinase activity as well as the inhibition of antioxidant enzymes activities in the presence of these drugs could be observed.

The obtained results give a new insight into the mechanisms of fluoroquinolones toxicity directed to pigmented tissues. Moreover, the presented differences in modulation of biochemical processes in melanocytes may be an explanation for various phototoxic activities of the analyzed fluoroquinolone derivatives in vivo.

Acknowledgments This work was supported by the Medical University of Silesia (Grant No. KNW-2-003/N/4/K).

Conflict of interest The authors declare that there are no conflicts of interest.

Open Access This article is distributed under the terms of the Creative Commons Attribution License which permits any use, distribution, and reproduction in any medium, provided the original author(s) and the source are credited.

\section{References}

1. Oliphant CM, Green GM (2002) Quinolones: a comprehensive review. Clin Pharmacol 65:455-464

2. Owens RC, Ambrose PG (2005) Antimicrobial safety: focus on fluoroquinolones. Clin Infect Dis 41:144-147

3. Thompson AM (2007) Ocular toxicity of fluoroquinolones. Clin Exp Ophthalmol 35:566-577

4. Reus AA, Usta M, Kenny JD, Clements PJ, Pruimboom-Bress J, Avlott M, Lynch AM, Krul CA (2012) The in vivo rat skin photomicronucleus assay: phototoxicity and photogenotoxicity evaluation of six fluoroquinolones. Mutagenesis 27:721-729

5. Van Bambeke F, Tulkens PM (2009) Safety profile of the respiratory fluoroquinolone moxifloxacin: comparison with other fluoroquinolones and other antibacterial classes. Drug Saf 32:359-378

6. Stahlmann R (2002) Clinical toxicological aspects of fluoroquinolones. Toxicol Lett 127:269-277

7. Dawe RS, Ibbotson SH, Sanderson JB, Thomson EM, Ferguson J (2003) A randomized controlled trial (volunteer study) of sitafloxacin, enoxacin, levofloxacin and sparfloxacin phototoxicity. Br J Dermatol 149:1232-1241

8. de Guidi G, Bracchitta G, Catalfo A (2011) Photosensitization reactions of fluoroquinolones and their biological consequences. Photochem Photobiol 87:1214-1229

9. Klecak G, Urbach F, Urwyler H (1997) Fluoroquinolone antibacterials enhance UVA-induced skin tumors. J Photochem Photobiol B Biol 37:174-181 
10. Leone R, Venegoni M, Motola D, Moretti U, Piazzetta V, Cocci A, Resi D, Mozzo F, Velo G, Burzilleri L, Montanaro N, Conforti A (2003) Adverse drug reactions related to the use of fluoroquinolone antimicrobials. Drug Saf 26:109-120

11. Traynor NJ, Barratt MD, Lovell WW, Ferguson J, Gibbs NK (2000) Comparison of an in vitro cellular phototoxicity model against controlled clinical trials of fluoroquinolone skin phototoxicity. Toxicol In Vitro 14:275-283

12. Neumann NJ, Blotz A, Wasinska-Kempka G, Rosenbruch M, Lehmann P, Ahr HJ, Vohr HW (2005) Evaluation of phototoxic and photoallergic potentials of 13 compounds by different in vitro and in vivo methods. J Photochem Photobiol B Biol 79:25-34

13. Plonka PM, Passeron T, Brenner M, Tobin DJ, Shibahara S, Thomas A, Slominski A, Kadekaro AL, Hershkovitz D, Peters E, Nordlund JJ, Abdel-Malek Z, Takeda K, Paus R, Ortonne JP, Hearing VJ, Schallreuter KU (2009) What are melanocytes really doing all day long...? Exp Dermatol 18:799-819

14. Rozanowska M, Sarna T, Land EJ, Land EJ, Truscott TG (1999) Free radical scavenging properties of melanin interaction of euand pheo-melanin models with reducing oxidising radicals. Free Radic Biol Med 26:518-525

15. Tolleson WH (2005) Human melanocyte biology, toxicology, and pathology. J Environ Sci Health 23:105-161

16. Simon JD, Peles D, Wakamatsu K, Ito S (2009) Current challenges in understanding melanogenesis: bridging chemistry, biological control, morphology, and function. Pigment Cell Melanoma Res 22:563-579

17. Hu DN (2008) Methodology for evaluation of melanin content and production of pigment cells in vitro. Photochem Photobiol 84:645-649

18. Larsson BS (1993) Interaction between chemicals and melanin. Pigment Cell Res 6:127-133

19. Beberok A, Buszman E, Wrześniok D, Otręba M, Trzcionka J (2011) Interaction between ciprofloxacin and melanin: the effect on proliferation and melanization in melanocytes. Eur J Pharmacol 669:32-37

20. Beberok A, Otręba M, Wrześniok D, Buszman E (2013) Cytotoxic effect of lomefloxacin in culture of human epidermal melanocytes. Pharmacol Rep 85:889-899

21. Wrześniok D, Beberok A, Otręba M, Buszman E (2013) Effect of streptomycin on melanogenesis and antioxidant status in melanocytes. Mol Cell Biochem 383:77-84

22. Ozeki H, Ito S, Wakamatsu K, Thody AJ (1996) Spectrophotometric characterization of eumelanin and pheomelanin in hair. Pigment Cell Res 9:265-270

23. Kim DS, Kim SY, Park SH, Choi YG, Kwon SB, Kim MK, Na JI, Youn SW, Park KC (2005) Inhibitory effects of 4-n-butylresorcinol on tyrosinase activity and melanin synthesis. Biol Pharm Bull 12:2216-2219

24. Busca R, Berlotto C, Ortonne JP, Ballotti R (1996) Inhibition of the phosphatidylinositol 3-kinase/p70(S6)-kinase pathway induces B16 melanoma cell differentiation. J Biol Chem 271:31824-31830

25. Chung SW, Ha YM, Kim YJ, Song S, Lee H, Suh H, Chung HY (2009) Inhibitory effects of 6-(3-hydroxyphenyl)-2-naphthol on tyrosinase activity and melanin synthesis. Arch Pharm Res 32:289-294
26. Buszman E, Beberok A, Różańska R, Orzechowska A (2008) Interaction of chlorpromazine, fluphenazine and trifluoperazine with ocular and synthetic melanin in vitro. Pharmazie 63: 372-376

27. Ono C, Tanaka MJ (2003) Binding characteristics of fluoroquinolones to synthetic levodopa melanin. J Pharm Pharmacol 55:1127-1133

28. Beberok A, Buszman E, Wrześniok D (2009) Interaction of norfloxacin and sparfloxacin with melanin in relation to phototoxic reactions. Ann Univ Mariae Curie Skłodowska Sectio DDD Pharm 4:87-92

29. Beberok A, Zdybel M, Pilawa B, Buszman E, Wrześniok D (2014) EPR characteristics of free radicals in DOPA-melaninmoxifloxacin at ambient level of UVA radiation. Chem Phys Lett 592:41-46

30. Yamaguchi Y, Hearing VJ (2009) Physiological factors that regulate skin pigmentation. BioFactors 35:193-199

31. Otręba M, Rok J, Buszman E, Wrześniok D (2012) Regulation of melanogenesis: the role of cAMP and MITF. Adv Clin Exp Med 66:33-40

32. Schiaffino MV (2010) Signaling pathways in melanosome biogenesis and pathology. Int J Biochem Cell Biol 42:1094-1104

33. Martinez LJ, Sik RH, Chignell CF (1998) Fluoroquinolone antimicrobials: singlet oxygen, superoxide anion and phototoxicity. Photochem Photobiol 67:399-403

34. Finaud J, Lac G, Filaire E (2006) Oxidative stress: relationship with exercise and training. Sports Med 36:327-358

35. Mari M, Colell A, Morales A, von Montfort C, Garcia-Ruiz C, Fernandez-Checa JC (2010) Redox control of liver function in health and disease. Antioxid Redox Signal 12:1295-1331

36. Hoogduijn MJ, Cemeli E, Ross K, Anderson D, Thody AJ, Wood JM (2004) Melanin protects melanocytes and keratinocytes against $\mathrm{H}_{2} \mathrm{O}_{2}$-induced DNA strand breaks through its ability to bind $\mathrm{Ca}^{2+}$. Exp Cell Res 294:60-67

37. Maresca V, Flori E, Briganti S, Mastrofrancesco A, Fabbri C, Mileo AM, Paggi MG, Picardo M (2008) Correlation between melanogenic and catalase activity in in vitro human melanocytes: a synergic strategy against oxidative stress. Pigment Cell Melanoma Res 21:200-205

38. Hsiao CJ, Younis H, Boelstreli UA (2010) Trovafloxacin, a fluoroquinolone antibiotic with hepatotoxic potential, causes mitochondrial peroxynitrite stress in a mouse model of underlying mitochondrial dysfunction. Chem Biol Interact 188:204-213

39. Yamakura F, Kawasaki H (2010) Post-translational modifications of superoxide dismutase. Biochim Biophys Acta 1804:318-325

40. Qin P, Liu R (2013) Oxidative stress response of two fluoroquinolones with catalase and erythrocytes: a combined molecular and cellular study. J Hazard Mater 252:321-329

41. Bedor DCG, Goncalves TM, Bastos LL, Miranda de Sousa CE, de Abreu LRP, Oliveira EJ, de Santana DP (2007) Development and validation of a new method for the quantification of norfloxacin by HPLC-UV and its application to a comparative pharmacokinetic study in human volunteers. BJPS 43:231-238

42. Stass H, Kubitza D (1991) Pharmacokinetics and elimination of moxifloxacin after oral and intravenous administration in man. J Antimicrob Chemother 43:83-90 